\title{
DIREITO E CIDADE. O POSITIVISMO ILUSTRADO E A CULTURA JURÍDICA BRASILEIRA NOS GRANDES CENTROS URBANOS (1850/1900)
}

\author{
LAW AND CITY. POSITIVISM ILLUSTRATED AND CULTURE LEGAL IN BRAZILIAN GREAT \\ URBAN CENTERS (1850/1900)
}

Vanderlei Martins ${ }^{1}$

\section{Resumo}

O artigo discute a inserção do positivismo no Brasil como ideário de vanguarda na formação intelectual brasileira. De maneira mais pontual, discute uma vertente do positivismo comteano no Brasil, denominada Positivismo llustrado e que, em nosso entendimento, é a interpretação mais apurada da doutrina de Augusto Comte entre nós. Nessa intenção, o artigo pontua a influência do positivismo ilustrado na cultura jurídica brasileira no período compreendido entre 1850 e 1900, período que marca a substituição do sistema monárquico pelo sistema republicano no Brasil e que contou com a participação decisiva dos positivistas nessa transposição. Como delimitação da exposição acerca da influência do positivismo ilustrado na cultura jurídica brasileira, o artigo toma como referências Pereira Barreto, Alberto Salles e Pedro Lessa, importantes propagadores do positivismo ilustrado no Brasil no período em questão e que estão entre os primeiros intelectuais positivistas brasileiros a discutir o Direito dentro da perspectiva racionalista comteana.

Palavras-chave: positivismo - direito - cidade - cultura - cultura jurídica - sociedade brasileira

\section{Abstract}

This paper discusses the integration of positivism in Brazil as cutting edge ideas in Brazilian intellectual formation. More timely manner, discusses an aspect of comtean positivism in Brazil, called Positivism Illustrated and, in our view, is the more accurate interpretation of the doctrine of Auguste Comte among us. This intention, the article points out the influence of positivism illustrated in Brazilian legal culture in the period between 1850 and 1900, a period that marks the replacement of the monarchical system by republican system in Brazil and had a decisive role in implementation of the positivists. How about the delimitation of exposure influences of positivism illustrated in Brazilian legal culture, the article makes references Pereira Barreto, Alberto Salles and Pedro Lessa, the major propagators illustrated positivism in Brazil in the period in question and who are among the first intellectuals to Brazilian positivists discuss the law within the rationalist perspective Comtean.

Keywords: positivism - right - city - culture - legal culture - Brazilian society

\footnotetext{
${ }^{1}$ Doutorado em Ciências pela COPPE/UFRJ. Professor Adjunto da Universidade do Estado do Rio de Janeiro. Parecerista das Revistas Direito da Cidade e Quaestio luris da Faculdade de Direito da UERJ. E-mail: martins1951@yahoo.com.br
} 


\section{O POSITIVISMO ILUSTRADO NO BRASIL (1850/1900)}

Os primeiros sinais de inserção do positivismo no Brasil se dá a partir de 1850. Época em que o Brasil tentava modernizar-se buscando adequar-se ao contexto capitalista moderno afirmado na Europa. É nesta etapa de nossa formação intelectual, que o positivismo se insere como ideário de vanguarda, impondo uma concepção social de progresso atrelado ao cientificismo racionalista moderno.

Tal inserção acontece através de alguns professores brasileiros, ex-alunos de Augusto Comte na Escola Politécnica de Paris entre 1832 e 1840, podendo ser citados Henri R. Guilon, Jose P. Almeida, Patrício de Almeida e Silva, Agostinho Roiz da Cunha, Antônio de Campos Belo e Antônio Machado Dias. Ao retornarem de Paris, propagaram os ideais comteanos através, principalmente, das Militar e Politécnica. Assim, foi um movimento que não nasceu no seio da elite cafeeira brasileira, uma vez que, seus primeiros seguidores eram filhos da nascente burguesia comercial. Tal elite que se afirma, expressava uma nova concepção burguesa, diferente daquela tradicional derivada das camadas aristocráticas. Serão os filhos da modesta burguesia comercial, os novos atores sociais em nossa formação intelectual a partir da segunda metade do século XIX.

Dos professores citados acima, a trajetória de José Patrício de Almeida é curiosa. Filho de senador do Império, fora a Paris para doutorar-se em Direito. Todavia, julgava pessoalmente, que o Brasil de seu tempo carecia muito mais de engenheiros para a nascente industrialização do que de bacharéis e resolveu, por conta própria e com a desaprovação do pai, ingressar na Escola Politécnica de Paris. Este exemplo isolado, de substituição do Direito pela Engenharia, antecipa o combate ideológico que seria sistematizado pelo médico Pereira Barreto, importante positivista ilustrado do período, contra o bacharelismo no Império (LINS, 1967:70).

Assim, a partir da segunda metade do século XIX, o positivismo começou a firmar-se no Rio de Janeiro através das escolas de natureza técnica. A gênese das profissões ensinadas alí estava muito mais próxima das ciências positivas do que do caráter humanístico presente em outras escolas como, por exemplo, a formação humanística recebida tradicionalmente pelos bacharéis em Direito nas escolas jurídicas. Isso posto, nos primórdios da afirmação do positivismo no Brasil, duas figuras serão inicialmente aludidas: o médico Pereira Barreto e o militar matemático Benjamin Constant.

Pereira Barreto (1840/1922), talvez tenha sido o mais importante divulgador do positivismo no Brasil no período em questão. Sua obra, "As três filosofias", pode ser vista como um guia prático para renovação de nossa cultura. Crítico feroz do catolicismo, sua concepção social tinha como alvo maior o fim da autoridade da Igreja Católica, principalmente através da supressão da tutela eclesiástica em 
relação ao ensino oficial, até então prevalente. Dizia ele, “...repulsão ao jesuitismo, eis o programa que desejaria ver posto em execução por todo o território brasileiro...É chegado o momento de proclamar as verdades filosóficas imanadas das ciências positivas" (COSTA, 1956:82).

Aqui um parêntesis. No período inicial do positivismo no Brasil, duas tendências se apresentavam no cenário nacional. Uma de cunho ortodoxo, de tendência religiosa, denominado Apostolado Positivista e liderada por Miguel Lemos e Teixeira Mendes. A outra tendência, de cunho filosófico, agia no ambiente acadêmico e tinha como expoentes Pereira Barreto e Benjamin Constant. Como nossa abordagem tem caráter científico, discutimos a segunda tendência, denominada Positivismo llustrado, conforme já aludido.

Voltando à Pereira Barreto, ele não possuía o "ardor apostólico" de Miguel Lemos, nascendo daí o antagonismo entre ambos. Barreto continuou fiel à filosofia positiva, de caráter científico, desprezando qualquer postura de tendência religiosa, tal como idealizavam Miguel Lemos e T. Mendes. Na verdade, o que Pereira Barreto buscava no positivismo era um método e não uma doutrina. Neste sentido, a Religião da Humanidade para ele era irrelevante, pois bloqueava o espírito relativista da busca da interpretação dos fatos políticos e sociais, sempre em constante mutação. Assim, a inserção do positivismo ilustrado na vida intelectual brasileira buscou dar uma nova organização ao ensino e à cultura brasileira. Sendo uma concepção marcadamente de ação, foi através da educação que se iniciou a propagação da ilustração positivista.

Sobre "As três filosofias", obra mais importante de Pereira Barreto, seu objetivo primeiro era definir um método dinâmico para o positivismo, inspirado no Curso de Filosofia Positiva de Augusto Comte. Segundo João Cruz Costa, “...O segundo volume das Três Filosofias revela excelente erudição, uma informação moderníssima e uma exposição muito clara do pensamento filosófico. Já nessa obra é fácil notar que o positivismo não se apresenta para P. Barreto tão exclusivo como na primeira parte das Três Filosofias. Littré é ainda o autor preferido, mas, ao seu lado, Pereira Barreto estuda Locke, Berkeley, Kant e Hartmann"(COSTA, 1956:97).

Apesar de severamente criticado por Miguel Lemos, "As três filosofias" foi amplamente difundida, influenciando significativamente a intelectualidade brasileira, inclusive os jovens que frequentavam a Faculdade de Direito de São Paulo, entre 1880 e 1890. Podemos dizer que inicia-se nesta ocasião, a influência do Positivismo na formação dos futuros bacharéis em Direito no país. Mas esta presença será retomada mais à frente, ao longo do artigo.

Já possuindo grande prestígio como médico cirurgião, Pereira Barreto foi convidado pelo influente Jornal Província de São Paulo, órgão do Partido Republicano, como seu colaborador. Assim, entre 1876 e 1922, escreveu artigos sobre medicina, ciências, filosofia, história, sociologia e costumes, sempre partindo da concepção positivista, e que o transformou em grande divulgador da doutrina 
positiva junto à intelectualidade brasileira.

Pereira Barreto se envolveu em várias polemicas ao longo de sua atuação como colaborador do jornal Província de São Paulo. Uma delas foi contra o projeto imperial de criação de uma universidade no Rio de Janeiro, proposto em 1870 e retomada sua discussão em 1881. A proposta imperial idealizava uma universidade com cinco faculdades: Direito, Medicina, Ciências Matemáticas e Naturais, Teologia e Letras.

Através de seis artigos na Província de São Paulo, atacou o projeto universitário enumerando as razões que o levavam a discordar da iniciativa. Considerava ele que, antes de tratar do ensino superior, era preciso cuidar dos ensinos primário e secundário, segmentos que deveriam ser priorizados na formação educacional da sociedade brasileira. Além deste motivo de ordem práticopedagógica, Pereira Barreto apresentava uma objeção de natureza teórico-filosófica, extraída da Lei dos Três Estados comteana.

Dizia Barreto, rejeitando categoricamente os ideais filosóficos advindos do mundo medieval, basicamente católico;

Antes de adotar qualquer medida, o político e o educador, assim como o filósofo, tem de apreender o que há de vivo e o que há de morto na sociedade, o que se destina a dar frutos e o que necessita ser abandonado, distinguindo no presente, o passado e o futuro. É preciso, como já ensinava Comte, examinar o passado e, graças a ele, conceber o futuro para compreender o presente, a fim de avaliar o que deve ser conservado hoje em função do amanhã, deixando de lado o que pertence a uma época perempta...Se quisermos pois, examinar com seriedade 0 problema da educação e, em especial, o da criação de uma Universidade no Brasil, é preciso compreender o que essa instituição significava no passado e ver se ela apresenta condições para permanecer, se é um elemento civilizatório. (LINS, 1967:101).

A rejeição dos positivistas ao projeto de universidade em 1881 tinha dois alvos precisos.

Quando P. Barreto argumenta e diz "deixando de lado o que pertence a uma época perempta", o faz apontando para o espírito católico que norteava o projeto e para o bacharelismo francês, da preferência do Imperador. Enfatizava ainda que a Universidade favoreceria apenas pequeno número de privilegiados, prejudicando a atenção que deveria ser dada ao ensino popular. Para ele, a criação de uma universidade no Brasil Imperial, seria um malefício ao povo brasileiro.

Nessa apreciação radical que fez ao projeto, foi enfático em suas considerações, ao dizer da impossibilidade de convivência simultânea entre ramos do conhecimento diferenciados, quando sentenciou de maneira categórica, "É esse monstro que se quer criar com a fundação de uma Universidade na Corte. Nela viverão, lado a lado, escolas positivas (Medicina, Ciências Matemáticas, Físicas e Naturais), escolas metafísicas (Direito e Letras) e até ultramontanas como a de Teologia. Ao 
invés de resolver nossos problemas, a Universidade complica-los-á... É preciso sacrificar a teologia e a metafísica e ensinar exclusivamente a ciência" (LINS, 1967:119).

A ânsia de "caminhar depressa", tal como proposto por ele, prescindia do conceito de prudência, o que abria a possibilidade para equívocos. O cientificismo exacerbado dos positivistas iniciais nada mais era do que a radicalização do discurso da razão científica moderna. Ao elegerem as ciências como único caminho para a realização da grandeza humana, retira do Homem sua natureza contemplativa-reflexiva, reduzindo-o a sujeito meramente operativo. No entender de Barreto, o programa de desenvolvimento econômico do Brasil, exigia uma preparação mais técnica e científica, tornando-se urgente, pois, a substituição do "reinado dos bacharéis" pelo mundo técnico determinado pelo discurso da ciência. Assim, a partir da crítica sistemática dos positivistas, o projeto de criação de uma universidade no Rio de Janeiro em 1881 foi arquivado.

Conforme já referido, Pereira Barreto foi o mais destacado representante do chamado positivismo-combativo no Brasil, pois tomava o Comtismo mais como teoria filosófica do que como um evangelho a ser propagado. Dotado de alto espírito crítico, sempre soube distinguir o certo e o errado na filosofia positiva, rejeitando sistematicamente os preceitos isolacionistas contidos no positivismo. Sempre que se deparava com uma contradição entre Augusto Comte e o progresso da ciência, Barreto preferia seguir a ciência; seu grande mérito foi ter sido um positivista que descobriu erros em Augusto Comte e que, além disso, lia outros livros fora daqueles da biblioteca positivista.

É inegável a influência do positivismo na ordenação da formação intelectual brasileira e, por extensão, na concepção pedagógica do país na segunda metade do século XIX. No âmbito educacional, a figura de maior destaque talvez tenha sido Benjamin Constant, militar, matemático e professor da Escola Militar, idolatrado pelos alunos e considerado em sua época como "verdadeiro formador de almas". Benjamin Constant também não pertencia à Igreja Positivista do Brasil, mas conhecia muito bem toda a obra de Augusto Comte.

Apesar disso, não estava convencido de que a humanidade devia imobilizar-se diante de Augusto Comte, tal como o fizera a Idade Média diante de Aristóteles. B. Constant fundou no Rio de Janeiro, em 1868, uma sociedade para o estudo do positivismo, o Instituto dos Meninos Cegos. Como diretor da instituição, pôs em prática suas conviçç̃es positivistas, passando a pregar um tipo de educação que continha como dogma a fé científica, atrelando o processo educativo à substituição de referenciais teóricas por conceitos concretos de aplicação imediata à realidade. Da mesma forma que sistematizava o positivismo, Benjamin Constant recebia, também, críticas sistemáticas à sua idealização.

Dentre essas críticas, podemos tomar como exemplo o discurso de Magalhães Taques, proferido na Câmara dos Deputados em 1871, como contraponto ao Relatório de Benjamin Constant 
enviado à Casa no mesmo ano, cujo teor atacava o modelo político-pedagógico brasileiro da época. Em sua crítica, Magalhães Taques sugeria o afastamento de Benjamin Constant da direção do Instituto dos Meninos Cegos e justificava sua posição dizendo que o positivismo objetivava a destruição da base moral da sociedade, pondo em seu lugar uma doutrina inconsistente. Segundo o deputado:

Os adeptos do positivismo não queriam saber da razão das coisas, não indagavam as causas, observavam os fatos e prescindiam de investigar o porquê. Não se elevavam ao conhecimento absoluto, limitando-se ao contingente. (MARTINS,1996:146).

Benjamin Constant propagou o Positivismo llustrado no Brasil através de duas frentes. No âmbito educacional, aqui já referido, mas também no âmbito político, sendo o responsável pela inserção ideológica do positivismo no cenário político nacional. Usando todo seu prestígio como professor de matemática na Escola Militar, propagou no ambiente político imperial, não só o positivismo, mas também os ideais republicanos. Apesar de sua ascendência militar, não tinha vocação às armas. Sua verdadeira vocação era o magistério, magistério de matemática. Ingressou na Escola Militar em uma época em que essa instituição começava a mudar seu perfil, ou seja, a substituição do militar combatente pelo militar letrado.

Proclamada a Republica, Benjamin Constant assumiu no Governo Provisório a pasta de Instrução Pública. Vale dizer que, em seu nascedouro, o sistema republicano brasileiro oscilou entre duas tendências: o liberalismo individualista de Rui Barbosa e o positivismo ilustrado de Benjamin Constant. À medida que a Republica avançava, a influência de Rui Barbosa se acentuava, fazendo com que Benjamin Constant permanecesse muito pouco tempo no governo provisório (MARTINS, 1996:167).

\section{POSITIVISMO ILUSTRADO E BACHARELISMO JURÍDICO NO BRASIL}

O positivismo ao se instaurar no Brasil empreendeu crítica sistemática à Monarquia, à Igreja Católica e à elite política-administrativa responsável pela sustentação institucional do Estado Imperial Brasileiro, composta basicamente pelos bacharéis em direito. Achavam eles que o sistema monárquico, a igreja católica e o bacharelismo jurídico se configuravam como entraves aos princípios da ciência moderna, única referência possível para a verdadeira modernização do Brasil, segundo os positivistas.

O Positivismo Ilustrado, vertente positivista que aqui nos interessa, não chegou a estabelecer uma tese consistente sobre o Direito, ao contrário, a crítica que essa tendência, e seus seguidores iniciais no Brasil, faziam ao Direito eram muito mais com fervor ideológico do que propriamente com solidez filosófica. Ao considerarem o Direito como fenômeno de natureza metafísica e subjetiva, logo, fora do discurso racionalista científico moderno, deveria simplesmente ser rejeitado como discurso científico, pois estava fora da nova ordem moralizante derivada da ciência moderna e entendido 
apenas como instituto que deveria subordinar-se à sociologia. Assim pensavam eles, reproduzindo a tese de Augusto Comte.

Muito longe estou de concluir, dizia Comte, das considerações precedentes, que a classe dos legistas não deva mais ter agora atividade política. Quis unicamente estabelecer que sua ação deve mudar de caráter...o estado atual da sociedade exige que a suprema direção dos espíritos deixe de pertencer aos legistas, mas isso não quer dizer sejam eles menos necessários, por sua natureza, para secundar, sob pontos de vistas muito importantes, a nova direção geral a ser estabelecida por outros. (COMTE, Tomo X, p. 71).

Para Augusto Comte, o Direito deve ser entendido como uma manifestação de natureza sociológica e, como tal, parte integrante da física social ou sociologia. Dentro desse pressuposto, se opõe à concepção jurídica dos direitos subjetivos do homem, que enfatiza o individualismo como princípio absoluto, independente da inserção do homem na convivência social. Dentro do chamado contratualismo norteador da Revolução Francesa, o homem seria servido pelo sistema políticoeconômico-social e não estar submetido a este. Ao se contrapor a esse princípio, Comte coloca a totalidade do sistema social acima do indivíduo, sujeitando-o. Em uma palavra, podemos dizer que, para Augusto Comte, a sociedade deve ser entendida como um organismo interconectado pelos diferentes segmentos que a compõem e não dentro da perspectiva contratualista, individualista por excelência.

Segundo Marchetti:

Comte não pretendia abolir o direito da vida social, mas sim alterar seu estatuto epistemológico. O fenômeno jurídico não mais seria objeto de estudo científico de uma ciência denominada direito - a jurisprudência - pois, sendo um fenômeno social, seu estudo científico passaria a ser competência da sociologia...O fundamento teórico do direito encontrar-se-ia predominantemente na sociologia, assim como a engenharia fundamentava-se na física. Tanto na engenharia, quanto no direito, existe uma dupla combinação entre a ausência de originalidade teórica e a especialização prática...A engenharia vale-se do aporte teórico da física para encontrar soluções práticas para problemas concretos. Do mesmo modo, o direito vale-se do aporte teórico da sociologia para encontrar soluções práticas para problemas concretos de sua especialidade. Em suma, esses conhecimentos intermediários não são ciências, mas técnicas, pois caracterizam-se por estarem dirigidos a determinada finalidade prática. ( MARCHETTI, 2001:50).

O grande senão da doutrina comteana é o radicalismo com que enquadra as ciências, seja para dar status a algumas, seja para desconsiderar outras, entendidas por ele como "abstrações". No caso do Direito mais especificamente, ao desconsiderar categoricamente o direito subjetivo como direitos apriorísticos, transformando-os em deveres, Comte prioriza a totalidade social, colocando o indivíduo submisso à um tipo de organicismo social radical, chamado por ele de Humanidade. Ao negar a relação 
de mão dupla que há entre a sociedade e o indivíduo, o positivismo comteano transformou-se em doutrina contraditória, autoritária por excelência. Ao negar a convergência natural existente entre os direitos individuais e os direitos sociais, a leitura que Comte faz do Direito é altamente discutível.

Pereira Barreto (1840-1923), talvez tenha sido junto com Benjamin Constant os principais arautos na inserção do positivismo comteano como ideário de vanguarda no Brasil, já dissemos aqui. O fato de ter sido colaborador do jornal "Província de São Paulo", mais tarde "O Estado de São Paulo", durante 36 anos, contribuiu muito para propagação do Positivismo entre nós. Sobre o Direito, é famosa a leitura que faz na obra "AOS LEGISTAS", onde chama o Direito de "jurisprudência absolutamente desnecessária dentro da nova ordem positivista". Para ele, o Direito em sendo um fenômeno de natureza metafísica, deveria ser suprido como esfera institucional relevante.

Tal concepção acerca do Direito, considerado por ele como um poder espiritual provisório que substituiu o poder teocrata, manifestou enorme curiosidade entre os juristas da época, que desejavam saber de que forma poderia a sociedade harmonizar-se sem a presença do ordenamento jurídico.

Segundo Marchetti, já citado:

Diante da falta de perspectiva de substituição da Jurisprudência(direito) no presente, Pereira Barreto, respondendo aos legistas preocupados com suas ideias de extinção do Direito, dirá que a filosofia positiva está longe, ao menos por ora, de pretender suprimir os códigos, dá-Ihes pelo contrário uma sanção irrefragável, fazendo depender a jurisprudência de uma lei da da evolução humana, lei tão natural e demonstrável como qualquer das leis físico-químicas ou biológicas. Portanto, Pereira Barreto reconhece a utilidade presente da jurisprudência e não propõe por ora sua eliminação, ainda que saliente algumas de suas deficiências incapazes, porém, de superar sua utilidade.

Se a jurisprudência justificava-se plenamente no passado, parcialmente no presente, cabe indagar se terá algum papel no futuro. Segundo Pereira Barreto, nada nos autoriza a asseverar que a jurisprudência não seja um mero instrumento de transição, como tudo quanto é criação da metafísica em geral. E assim levanta-se naturalmente uma terceira questão, a saber se, em um futuro longínquo, a jurisprudência apresentará os mesmos títulos de necessidade social, para preencher o mesmo ofício, que preencheu no passado e ainda preenche presentemente. É esta uma questão que merece ocupar a atenção de todos os jurisconsultos verdadeiramente dignos deste nome. Não se trata aqui dos interesses de uma classe, trata-se do bem comum a todas as classes da sociedade (MARCHETTI, 2001:57).

Vale dizer que, para Pereira Barreto, a metafísica, aí incluído o Direto, era simplesmente uma variação da Teologia. Nesse sentido, ambas, Teologia e Metafísica e por extensão o Direito, importantíssimas no passado, mas que devem ser vistas no presente como obstruções para a nova ordem científica moderna condutora do progresso da humanidade. Para ele, a Teologia e a Metafísica 
estão dentro do ciclo evolutivo da humanidade e que foram naturalmente superadas pela lógica positivista moderna. No caso do Direito, o fim de seu ciclo evolutivo ainda está em curso, mas sua supressão seria apenas questão de tempo, segundo ele.

O raciocínio de Pereira Barreto segue pontualmente o princípio positivista de análise da humanidade mediante uma lógica evolucionista rígida e pré-concebida. Em tal análise, parte da Grécia Clássica, passa pelo Império Romano, atravessa a Idade Média e chega à Idade Moderna tentando demonstrar através dessa evolução positiva, a importância do Direito e sua possível supressão. Mostra, então, que a tendência de estabelecimento de códigos legais vai surgindo à medida que o processo civilizatório da humanidade evolui. Sendo, portanto, o Direito, um a posteriori ao advento civilizatório. Nessa evolução civilizatória, a humanidade primeiro, em seu período clássico, na Grécia, substitui o pensamento teológico pela autoridade metafísica legalista, chamada por ele de legalismo civilista ou "legislação civil". Em Roma, em seus primórdios, o fenômeno se repete, o direito romano surge como adequação moral para a diversidade social que caracterizava os indivíduos romanos, ou seja, serão os legisladores romanos que darão unidade ao que seria mais tarde conhecido como Império Romano.

No período medieval, Pereira Barreto segue em sua tese evolucionista afirmando que o mesmo processo se repete. O desenvolvimento do ambiente social católico, fruto do progresso material medieval, impôs o estabelecimento de uma outra autoridade diferente da autoridade católica. Essa nova autoridade, de natureza metafísica, passa a ser exercida pelo Direito, segundo ele, representante da vontade civil. Dessa forma:

Se propagou o ensino do Direito Romano, o que permitiu à sociedade prosseguir a sua marcha, pois estava garantida a evolução do progresso, ficando ao mesmo tempo garantida a ordem. O que se conclui dessa análise histórica empreendida por Pereira Barreto foi que na legislação, mais uma vez, se achou o fio condutor do progresso social. ( MARCHETTI, 2001:59).

O que Pereira Barreto se esforça para demonstrar com sua tese é que ao longo da trajetória histórica da civilização ocidental, o poder de natureza religiosa (teológico) sempre foi substituído por um poder de natureza jurídica (metafísico) como processo de adequação da ordem moral ao progresso social em curso. Para ele sempre que a ordem de natureza moral entrava em colapso, o Direito assumia a responsabilidade pelo restabelecimento da unificação social.

A concepção positivista-evolucionista de Pereira Barreto chega ao mundo moderno onde vai discutir a presença de do Direito dentro da modernidade nascente. Para ele, vivenciamos também na aurora do mundo moderno um processo de transição onde a harmonia social está ameaçada, que ele chama de "ruptura da unidade moral", decorrente do conflito ideológico inconciliável entre o catolicismo, o protestantismo e o cientificismo. Conflito esse que atinge seu auge por volta de 1700. Nesse momento, o Direito ainda se mostra fundamental como equilíbrio social. 
Segundo Barreto, e através de Marchetti, já citado:

Como pôr fim a esse estado de anarquia moral que impede à sociedade manter sua unidade sem auxílio do direito? Para Pereira Barreto a origem remota dos males sociais é a ignorância...Onde existe ignorância, inexiste unidade moral, e vice-versa. Por isso afirmou que 'é a unidade intelectual preâmbulo obrigatório da unidade moral'. Mas onde encontrar a tal "unidade intelectual"? A resposta de Pereira Barreto é clara e precisa: na ciência...somente a ciência é capaz de proporcionar uma 'fé demonstrável'...A fé demonstrável, ou fé científica, será o resultado decorrente do domínio das ciências na direção das inteligências, sem qualquer resíduo de teologia ou de metafísica...Se a fé na ciência tiver amplo domínio, então a unidade moral estará garantida. (MARCHETTI, 2001:78).

Como forma de legitimar sua concepção de sociedade ideal, Barreto retorna à Idade Média para afirmar que, se foi possível à filosofia católica controlar a sociedade através de uma concepção de mundo apoiada em princípios transcendentes e não-factuais, mais possível ainda será educar e estabelecer a harmonia social mediante uma fé de natureza pragmática, factual e absolutamente demonstrável derivada da razão científica. Nesse sentido, segundo ele, o Direito perde sua importância institucional, tendendo, assim para sua supressão como referência social.

Assim, profetiza o ocaso da ordem legalista, derivada do Direito, com o triunfo da ordem científica derivada da ciência moderna. Simples assim. Da confiança na ciência moderna irá derivar o conjunto harmonioso intelectual, que propiciará a harmonia moral, que, por sua vez, irá impor a harmonia social. Vale dizer que, dentro da perspectiva definida por êle, a supressão do Direito ocorrerá naturalmente a partir do estabelecimento pleno do estado positivo(científico), uma vez que, por se tratar de um instituto de natureza metafísica, logo, será dispensável na nova ordenação social.

Apesar de gêneses distintas, existe um ponto de convergência entre a ciencia moderna e o Direito, ou seja, são institutos de natureza intelectual, que atuam de maneira pontual nos estágios que compõem o processo civilizatório da humanidade. Dentro deste raciocínio, afirma Barreto, através de Marchetti, enquanto o Direito é o poder espiritual típico do estado metafísico, a ciência é o poder espiritual típico do estado positivo. O que ocorre, de fato, então, é apenas a substituição de autoridades na gerência da sociedade. A substituição de um poder de natureza intelectual por outro. Assim foi desde os primórdios da civilização ocidental, onde o paganismo clássico foi suplantado pelo catolicismo medieval e estes suplantados pelo legalismo jurídico que, será naturalmente suplantado pelo "sacerdócio" positivo. Pereira Barreto é categórico e finalista ao afirmar que o poder intelectual é pressuposto permanente no sistema societário, o que muda, na verdade, são as instituições responsáveis pelo controle deste poder intelectual. Por extensão, ainda segundo Marchetti, para Pereira Barreto, o Direito é um órgão do organismo social encarregado de exercer o poder espiritual 
(intelectual) na fase de transição entre as etapas teológica e positiva e que perderá sentido a partir de sua substituição pelo poder da ciência moderna.

O que impressiona no pensamento de Pereira Barreto, é a rigidez positivista-evolucionista de sua concepção social ideal para o mundo moderno, não abrindo qualquer perspectiva de natureza sensitiva ou espiritual, características inerentes à natureza humana. Para ele, qualquer forma de pensamento propenso a se contrapor ao racionalismo científico moderno deve ser entendido como forma de "ignorância" intelectual. Tentar enquadrar a sociedade, dando-Ihe a mesma feição cartesiana da ciência moderna, nos leva a pensar como sendo um contrassenso. As contradições provocadas por impulsos instintivos, não são características do cientificismo moderno, sabemos, mas são características históricas da humanidade e que, interferem de maneira significativa na organização de qualquer sociedade.

Se Pereira Barreto entendia que o Direito, sob qualquer aspecto, deveria simplesmente ser desconsiderado dentro do modelo social idealizado por Augusto Comte, positivistas ilustrados, seus contemporâneos, tinham interpretação diferenciada acerca da ordem jurídica, ou seja, talvez fosse possível adequar o discurso do Direito ao sistema social positivista comteano. Alberto Salles e Pedro Lessa, são referências importantes dentro dessa perspectiva. Vale dizer que, esses positivistas ilustrados brasileiros, da mesma forma que Pereira Barreto, partem da concepção organicista da sociedade para elaborarem suas teses. Partindo do pressuposto de que o Direito é uma técnica social e não uma ciência independente, Alberto Salles e Pedro Lessa consideram possível o estabelecimento de um ordenamento jurídico positivo, desde que condicionado aos princípios da Sociologia, que é a síntese de todos os estudos de natureza social dentro da enciclopédia de Augusto Comte.

Sobre Alberto Sales(1857/1904), fazia parte de uma geração de estudantes da Faculdade de Direito em São Paulo que foram fortemente influenciados pelas ideias positivistas de Pereira Barreto. Dessa geração, podemos citar Júlio de Castilhos e Borges de Medeiros (inserção do positivismo no cenário político gaúcho), Silva Jardim, Lúcio de Mendonça, João Pinheiro, Rivadávia Correa, entre outros, que marcaram presença no cenário político da época. Vale dizer, que as duas faculdades de direito existentes no Brasil nessa época, Olinda e São Paulo, tinham perfis definidos. Enquanto Olinda preparava para a magistratura, a faculdade paulista formava o bacharel para a vida política.

Alberto Sales, irmão do presidente Campos Sales, foi importante propagandista da República antes de sua efetiva inserção como sistema político brasileiro em substituição à Monarquia em 1889. O que nos interessa, de fato, em nossa discussão, é o viés jurídico de seu pensamento positivista e, nesse sentido, sua obra ENSAIO SOBRE A MODERNA CONCEPÇÃO DO DIREITO, é referência significativa.

Para Alberto Sales, segundo Miguel Reale, o Direito ao assumir a condição de unificador de interesses interligados na convivência social, se apresenta como referência na regulação sistemática e 
contínua das diferenças. Nesse sentido ou nesse propósito, influenciam na origem do Direito, o interesse, o costume, a religião, a moral e a opinião pública. Para Sales, o Direito como necessidade social, existe independente do Estado, mas que só se torna autoridade social depois que o Estado legitima sua autoridade, reconhecendo sua necessidade.

Ainda dentro desse raciocínio, ainda através de Miguel Reale, Alberto Sales teoriza:

O poder público não assegura, não garante condição alguma de existência, quer ao indivíduo, quer à sociedade; apenas regulamenta, sistematiza, coordena, disciplina essas condições, que aparecem naturalmente, espontaneamente, independentemente de sua intervenção. O direito não é um complexo de garantias, mas sim um sistema de equilíbrio. (REALE, 1959:30).

Falta, talvez, à essa reflexão jurídica de Alberto Sales, os vieses históricos e filosóficos para ir além de seu condicionamento científico-positivista e fazer confluir princípios de natureza ético-sociais à sua visão legalista.

A rigidez de seu pensamento se manifesta categoricamente quando enfatiza que:

Se é lei do cosmos o sacrifício dos mais débeis; se os antagonismos e as guerras são inevitáveis, e além do mais, fatores de aperfeiçoamento e crescimento da espécie, pela sobrevivência dos mais aptos, para o desenvolvimento espontâneo das próprias forças civilizadoras, mister é que o Direito não seja transformado em garantia dos mais fracos... O direito deve deixar que se opere livremente o processo natural e constante da eliminação, em vez de constituir-se elemento perturbador da economia social e sim de cooperação social, mas de modo que prevaleçam os mais aptos. (REALE, 1959:33).

Recorrendo ainda à Miguel Reale, em sua abordagem em ENSAIO SOBRE A MODERNA CONCEPÇÃO DO DIREITO, aponta que:

É na conclusão de seu ensaio, ao elaborar uma síntese geral, que Sales põe o problema da validade ou significado histórico da Ciência do Direito. Concorda com Pereira Barreto, quanto à evolução histórica da sociedade rumo ao sacerdócio positivista, mas discorda quanto à extinção do Direito em sua função social. Como sistema de equilíbrio de forças individuais, o Direito é imprescindível ao organismo social e, em vez de ser considerado como forma de poder, só pode ser interpretado cientificamente como função, como fenômeno puramente dinâmico que encontra no Estado o seu órgão especial. E como todo positivista, reitera a conviç̧ão de que, um dia, o elemento coercitivo, que ainda é a única fonte de autoridade, do prestígio e da força da legislação, tende, contudo, a desaparecer progressivamente, de maneira que a força da garantia material venha a ser substituída pela uniformidade de opiniões e pelo prestígio das verdades demonstráveis (REALE, 1959:36).

Leia-se pelo estado positivo condutor do racionalismo científico moderno.

Pedro Lessa (1859/1921), foi contemporâneo acadêmico de Alberto Sales, frequentaram a 
mesma turma de direito na Faculdade de São Paulo, formando-se em 1883. Vale dizer que, a partir dessa época, o ensino jurídico começa a perder progressivamente o tradicional modelo coimbrão, passando a ser interpretado pelos pressupostos da Filosofia Positiva. Nessa mudança do paradigma pedagógico, é que Pedro Lessa se situa como professor de Filosofia do Direito na faculdade paulista. Lessa, em suas formulações, discorda de alguns conceitos comteanos, principalmente em relação à lei dos três estados. Para ele, religião, filosofia e ciência sempre coexistiram ao longo do processo civilizatório, não podendo, pois, serem considerados etapas ou processos desvinculados historicamente. Em Lessa, metafísica e religião são fundamentos importantes dentro do processo civilizatório, principalmente a religião em sua gênese de confortar e aplacar as angústias humanas. Em relação à metafísica, reconhece sua incompatibilidade com o rigor científico, mas não despreza seu princípio maior que é de buscar sempre as causas primeiras.

Pedro Lessa pode ser considerado como um pensador jurídico que se propôs repensar a filosofia positiva de Augusto Comte, bem como discuti-la no âmbito do Direito. Nesse sentido, sua visão sobre o Direito considera pressuposto obrigatório uma "aproximação" com a realidade social. Nesse sentido, destaca a sociologia jurídica como matéria capaz de dar ao Direito status de ciência através da pesquisa científica.

"A verdadeira Ciência do Direito, a que não se desenvolve no foro, nem nas obras dos juristas técnicos, não é dedutível de preceitos vigentes; só pode ser indutiva, gozando de relativa autonomia no campo comum da Sociologia, à qual compete o conhecimento das leis gerais que ordenam a sociedade. Sem ser mero capítulo da Sociologia, a Ciência do Direito, como cada uma das ciências sociais, 'se consagra ao estudo das leis que regem uma determinada classe de fenômenos, está encerrada em uma esfera limitada, particular, tem um domínio seu. O Direito se ocupa das leis, a que estão subordinados os fatos sociais desta determinada classe: as condições de vida e desenvolvimento da sociedade e do indivíduo, dependentes da vontade humana, e já garantidas, ou que é necessário o sejam, pela fiança física do Estado' (REALE, 1959:53).

Assim, no entendimento de Pedro Lessa, o Direito ganha status de ciência ao adotar, de forma associada, os métodos indutivo e dedutivo. Através da indução, os fatos seriam observados e a partir dessas observações, as leis seriam criadas. Já através da dedução as leis criadas a partir da observação indutiva, seriam formalmente aplicadas nos fatos particulares. Acreditava ele que através dessa sistematização positiva de priorizar os fatos sociais na definição do Direito, estaria neutralizando as 'ideias extravagantes' de natureza filosófico-jurídicas que dominavam a literatura jurídica da época, principalmente àquelas doutrinas de origem metafísica. Para Lessa, o Direito é a garantia das necessidades sociais e quando essa necessidade é perfeitamente normatizada, tende a se perpetuar através dos tempos, podendo ocorrer apenas algumas adequações compatíveis com o próprio tempo. 
Segundo Marchetti, já citado, Pedro Lessa:

Sustenta a existência da 'repetição dos mesmos institutos jurídicos, em seus lineamentos gerais, em sociedades das mais afastadas épocas, das mais diversas raças, das mais diferentes culturas. É que, a despeito das dificuldades de bem apurar as exigências da vida social, e de bem formular preceitos jurídicos que as satisfaçam, há certas necessidades sociais tão intensas e evidentes, que se impõe à inteligência humana em todos os lugares e em todos os tempos. (MARCHETTI, 2001:157).

Podemos dizer que o ponto de partida do pensamento jurídico de Pedro Lessa é, invariavelmente, a realidade social e que essa realidade social é concebida por uma lei natural e que essa lei de natureza cósmica, não deve ser confundida com direito natural. É justamente essa lei natural antecedente que serve de referência ao estabelecimento de um Direito de natureza normativa, ou seja, a confluência entre o chamado mundo de natureza moral/costumeira com o mundo de natureza jurídica, permite a criação de princípios legais indispensáveis à convivência social. Dentro dessa concepção de Lessa, sem o Direito não há vida social organizada. Para ele, o Direito é a referência orgânica maior da sociedade, ou seja, o Direito deve ser organizado de acordo com princípios de natureza científica, para ser estabelecido, conforme suas palavras, 'como um princípio organizador das coletividades de indivíduos, sem o que tal conjunto não passaria de um aglomerado desorganizado, fadado ao extermínio'.

Assim, o estudo científico do Direito identifica-se com a descoberta das leis naturais que possibilitam a passagem da aglomeração de indivíduos para uma organização de indivíduos, que é a sociedade. Nesse sentido, diz Pedro Lessa, que 'o Direito é uma condição de vida indispensável ao homem: verifica-se necessariamente na sociedade. A esse estudo científico do direito Pedro Lessa chamou de "filosofia do direito" (MARCHETTI, 2001:161).

\section{ALGUMAS CONSIDERAÇÕES FINAIS}

No período privilegiado nesse artigo, falar em Ilustração no Brasil significava sinalizar para um desejo de substituição da ordem imperial por uma nova ordem de natureza republicana espelhada na Europa, principalmente na França. Tal período na formação intelectual brasileira marca a gestação de uma nova burguesia avessa à Monarquia e ao poder aristocrático que lhe representava. No período de afirmação dos ideais liberais franceses, expressos pela Revolução Francesa, surge, também na França, uma filosofia que também se apresenta como modelo civilizatório ideal para a Modernidade, surge a Filosofia Positiva de Augusto Comte, que no Brasil transformou-se em ideário de vanguarda e referência para a Proclamação da República em 1889.

Podemos dizer que o Positivismo llustrado, uma das vertentes do positivismo afirmado no 
Brasil, se estabeleceu de maneira definitiva entre nós a partir de 1870 com o médico Pereira Barreto, através de seu livro AS TRES FILOSOFIAS, onde, em uma palavra, propunha uma ordem de natureza científica em um plano superior à ordem social, na organização da sociedade. Através do racionalismo científico comteano, de caráter evolucionista, acreditava ser possível superar o estado "anacrônico" de natureza metafísica representado pela Monarquia e atingir o estado positivo de natureza científica a ser representado pela República.

O positivismo se estabeleceu no Brasil sem resistências significativas porque em 1850, e décadas imediatamente seguintes, era flagrante a fragilidade das instituições brasileiras, realidade essa que obstruía qualquer tentativa de sustentabilidade do sistema monárquico brasileiro, pois faltava-lhe unidade política para preservação das instituições sociais de forma harmônica. Foi assim, que, de dentro de uma espécie de baú brasileiro, repleto de ideais derivados do racionalismo científico moderno afirmado na Europa, que, o ideal positivista comteano se afirmou entre nós. A ordem por base e o progresso por fim, passou a ser o lema norteador da republica positivista brasileira proclamada.

Nesse sentido, a grande novidade trazida pelo positivismo ilustrado para a formação intelectual brasileira foi o discurso da razão científica, já afirmado na Europa, e que serviu como contraponto à cultura predominante até então, basicamente apoiada na filosofia católica-tomista medieval. A inserção do racionalismo científico moderno, via positivismo comteano, foi, assim, uma novidade impactante e profunda, que alterou substancialmente as instituições sociais brasileiras, inclusive o Direito. Podemos dizer que o Positivismo llustrado, a partir de sua gênese de natureza pragmática, introduziu no Brasil uma cultura baseada na funcionalidade objetiva moderna, em detrimento de uma cultura de natureza transcendente e metafísica, prevalente até o advento da Republica.

Mesmo se estabelecendo como pensamento realista e factual, ao Positivismo llustrado faltou o chamado "fôlego filosófico", uma vez que partia, invariavelmente, da perspectiva científica e dela não se afastava. O que realmente importava para a doutrina positivista na época era a realidade palpável e passível de demonstrabilidade. Qualquer princípio fora dessa perspectiva era entendido como de natureza teológica ou metafísica, logo, desprezível. Podemos dizer que o positivismo instaurado no Brasil como pensamento de vanguarda, representava a radicalização do discurso da razão científica moderna que, na Europa, a partir do século XVIII, já estava sendo rediscutido, e ali não provocou nenhuma repercussão significativa. Augusto Comte na França era sim, considerado um filósofo de "segunda linha".

No Brasil, entretanto, a ideia de avanço em busca de um processo civilizatório modernizante, passava obrigatoriamente, pelo ideário positivista, ou seja, o progresso científico como referência 
maior para o desenvolvimento econômico-industrial, que por sua vez seria a referência maior para o desenvolvimento pleno da sociedade brasileira. Assim, através de um capitalismo moralizante, o bemestar material seria a base da felicidade plena. Através da lógica funcionalista e objetiva da ciência moderna, a sociedade brasileira atingiria sua plenitude, acreditavam os positivistas, desconsiderando, equivocadamente, valores e princípios de natureza subjetiva que dão pleno sentido à existência humana.

Na verdade, o ideário positivista representava ou expressava um princípio filosófico autoritário e fechado em si mesmo, haja visto as críticas que Augusto Comte dirigiu ao espírito da Revolução Francesa. Entre nós, impregnou nas elites da época uma mentalidade autoritária e avessa aos discursos antagônicos. Nesse sentido, podemos citar Tobias Barreto como contraponto importante à essa mentalidade radicalmente cientificista aqui estabelecida. Tobias Barreto mediante seu pensamento filosófico e jurídico, expresso em suas obras, pode ser considerado expressão maior de uma concepção de mundo universalista, que vai além de pontuações filosóficas restritivas, tão comuns nas elites da época.

Dentro dessa perspectiva, o Positivismo llustrado pode ser considerado como filosofia restritiva, uma vez que transforma o conceito de positividade científica como único discurso capaz de conduzir o processo civilizatório brasileiro e, por extensão, só reconhecendo a legitimidade do Direito a partir de sua submissão aos princípios dessa positividade científica. A partir da inserção do Positivismo llustrado na cultura jurídica brasileira, começam a surgir novas teorias acerca da função do Direito na organização social do Brasil, em detrimento de uma cultura de natureza eclética, até então prevalente. A substituição do "romantismo abstrato" pela "racionalidade concreta dos fatos" é o viés condutor dessa transposição voltada para implantação de novos referenciais à cultura jurídica, referenciais esses sempre derivados da ilustração positivista.

\section{REFERÊNCIAS}

ALFREDO, Bosi. Dialética da colonização, São Paulo: Cia das Letras, 1994.

CARVALHO, Jose Murilo de. Formação das almas, São Paulo: Cia das Letras, 1990.

GUIMARÃES, Aquiles Cortes. Pequenos estudos da filosofia brasileira, Rio de Janeiro: Nau, 1998.

AZZI, Riolando. A concepção da ordem segundo o positivismo ortodoxo brasileiro, São Paulo: Loyola, 1980.

LINS, Ivan. História do positivismo no Brasil. São Paulo: Companhia Editora Nacional, 1967.

COSTA, João Cruz. Contribuição à história das ideias no Brasil. Rio de Janeiro: José Olímpio, 1956. 
MARTINS, Vanderlei. Primórdios do ensino técnico e das ciências no Rio de Janeiro. Rio de Janeiro: COPPE/UFRJ, 1996.

COMTE, Augusto. Plan des travaux scientifics nécessaires pour reorganiser la societé. OAC, Tomo X, pág. 71. s.d.

MARCHETTI, Maurizio. O estatuto do Direito no comtismo brasileiro. Campinas: Unicamp, 2001.

REALE, Miguel. Pedro Lessa e a filosofia positiva em São Paulo, in: Filosofia em São Paulo. São Paulo: Grijalbo, s.d.

Trabalho enviado em 30 de maio de 2015.

Aceito em 21 de junho de 2015. 